\title{
A Study of the Effectiveness of PBL and MAKER Classes Based on Flipped Learning
}

\author{
Jeong-Phil Hue \\ Department of Center for Teaching and Learning Ulsan University, Ulsan, Korea
}

Purpose: The purpose of this study was to find whether a team assignment in a Flipped Learning class using Project Based Learning PBL or MAKER has a greater effect on improving interest and class satisfaction than in the existing class.

Methods: As an alternative to increasing the level of interest in the existing Flipped Learning class, the team project activity was operated as a PBL or MAKER project. The activityrest andtiveness was investigated through the results of pre- and post-interest surveys and a satisfaction survey.

Results: The study participants in the Flipped-based PBL and MAKER classes, showed much greater interest and satisfaction than those in the existing Flipped Learning classes.

Conclusion: The study results indicated that the selection of a class application offering a wider variety of teaching methods suitable to the subject and the combined application of several teaching methods complemented the shortcomings of existing teaching methods and maximized their strengths.

Keywords: Flipped Learning; Problem-Based Learning; MAKER Education; Teaching Method

\section{INTRODUCTION}

In the face of the Fourth Industrial Revolution, many innovative teaching methods are emerging in education as the human resources demanded for the times change. As constructivism-based interaction, collaboration, and self-direction were emphasized, the paradigm of education changed. In the 1990s, the more learner centered PBL method appeared. STEAM,

emerging as convergence education involving science, engineering, technology, the arts and mathematics, was emphasized in the 2000s.

In the 2010s, along with the Fourth Industrial Revolution, teaching methods such as Flipped Learning and MAKER education appeared; these are the foundations of maximized constructivism, emphasizing creativity and an interactive sharing culture. Many universities are paying great attention to and investing in the introduction and application of these innovative teaching methods.

MAKER education and Flipped Learning are teaching methods that Korean universities have applied to college classes and confirmed their effectiveness in increasing academic achievement and interest (Tawfik \& Lilly, 2015). Flipped Learning relies on first presenting content through videos outside the classroom and then conducting classes mainly reliant on presentations and discussions. It has been reported to have had a positive effect (Toqeer, 2013). It has also been reported that MAKER education improves academic achievement and increases interest in learning through self-direction in learning that encourages creative processes and a need to respond to the experience of failures while developing problem-solving skills (Lee \& Yoon, 2017).

Recent innovative teaching methods taken up by Korean universities is divided into two op-

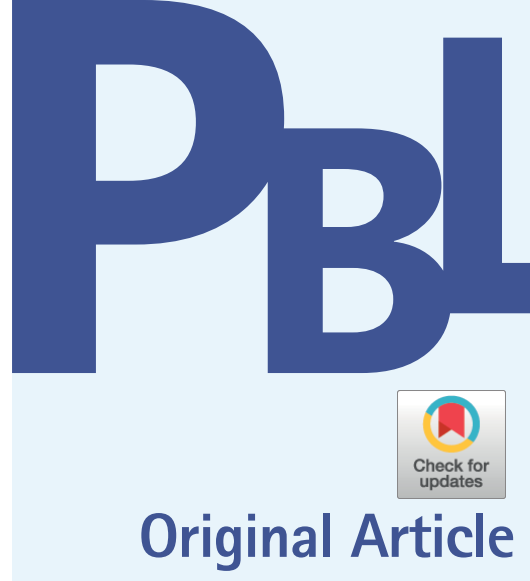

pISSN 2288-8675 · elSSN 2508-9145

J Probl Based Learn 2021;8(2):53-61

https://doi.org/10.24313/jpbl.2021.00038

Received: March 16, 2021

Revised: April 7, 2021 (1st) June 25, 2021 (2nd)

Accepted: July 3, 2021

Corresponding author:

Jeong-Phil Hue

Department of the Center for

Teaching and Learning Ulsan

University, 93 Daehakno, Nam-gu,

Ulsan 44610, Korea

Tel: 82-52-259-1342

E-mail: mathfeel@ulsan.ac.kr
(C) 2021 International Society for Problem-Based Learning

(c) This is an Open Access article distributed under the terms of the Creative Commons Attribution Non-Commercial License (http://creativecommons.org/licenses/ by-nc/4.0/) which permits unrestricted non-commercial use, distribution, and reproduction in any medium, provided the original work is properly cited. 
tions: PBL and Flipped Learning. Seoul National University, Yonsei University, and Korea University designate Flipped Learning as an innovative teaching method. Other universities, including Hanyang University, cite PBL as a major innovation in teaching methods, their development and operationalization. They are striving to spread these curriculum changes so students can strengthen their competencies suited to the future.

However, there are many differences in the effectiveness of innovative teaching methods depending on the characteristics of subjects or the learners' tendencies, necessary factors to consider to effectively introduce and appropriately apply any new methods.

Therefore, this study examined not only offline activity classes involving simple active learning but also PBL tasks that can increase problem solving ability through real life interaction and interest according to each subject's unique content. This research studied the effect of a new teaching method that combined several educational approaches by adding a Flipped-based PBL class and a Flipped-based MAKER class employing the recently highlighted MAKER approach as a class activity. This comprehensive teaching method can foster creativity in preparation for The Fourth Industrial Revolution.

The present study compared the results of the new combined approach (involving Flipped Learning, PBL, and MAKER education tailored to the subject) with those of the existing Flipped Learning class to see if the effect was maximized when innovative teaching methods are well-integrated. Given the impact of COVID-19, we conducted online project activities through Flipped Learning-interaction, and we also tried to operationalize Flipped Learning in the online mode. Surveys provided feedback on satisfaction with the innovative approach.

\section{Research Questions}

1. Are flipped-based PBL and MAKER classes more effective in improving interest than existing flipped learning classes?

2. Did the Flipped-based PBL and MAKER classes rate higher in class satisfaction than the existing Flipped Learning classes?

\section{Study Limitations}

This study targeted learners at a certain level at a specific university in a particular area. Due to COVID-19, class activities were conducted online, so there are limitations to the generalization of study results.

\section{METHODS}

To begin this section, the characteristics of the innovative teaching methods are examined before the perceptions of effects of ap- plying Flipped-based PBL, MAKER classes, an innovation at Ulsan University, are analyzed.

\section{Flipped Learning}

The definition of Flipped Learning is literally interpreted as "upside-down learning." It is a teaching method that reverses the traditional teacher-centered education approach. As a learning model that performs tasks through action (Johnson \& Renner 2012), the classroom in the present study is defined as a mixed educational environment in which an activity- centered class is conducted after pre-learning using various technologies appropriately (Crompton \& Giannakos, 2014). The general characteristics of Flipped Learning and the results of various studies on its educational effects can be broadly divided into four categories.

First, Flipped-Learning is provided to learners in the form of prerequisite learning through various media (Bergmann \& Sams, 2012). In general, video lectures developed and produced by instructors are actively used, but other content, lecture materials, and printed materials on the internet can also be used. Through these pre-learning materials, learners have the potential to understand the concepts to be learned.

Second, in the classroom, a team is formed, and learner activities take place based on collaboration with peers (Frydenberg, 2013). Learners who understand the concept in advance participate in in-depth learning by using and applying various types of activity for learning in the classroom. At this time, the instructor should play the role of a facilitator who provides feedback to learners through observation, not taking the role as a lecturer.

Third, the class's focus should be the learner, not the instructor (Lee, 2015). In other words, because learners voluntarily learn through various activities, both customized education tailored to the learner's level, and the adjustment of class activities according to individual learner requirements are possible.

Fourth, the interaction between learners and instructors is emphasized (Wilson, 2013). In the classroom, students, professors, and learners share opinions and solve a given task through various discussions and collaborations, thereby developing deeper thinking and problem-solving skills and promoting multilateral relationships.

To summarize Flipped Learning's features, learners are exposed to content and concepts in advance through self-directed learning activities delivered in various forms. In the class, they extend the responsibility for learning themselves through activities such as learner-centered collaboration and discussion. It can be an effective educational method that improves problem-solving skills and enhances the relationship between instructors and learners. 


\section{Problem-Based Learning}

In PBL, learners seek solutions to problems through active participation and cooperation based on the development of their critical thinking and problem-solving skills. The emphasis is on practical problem solving and a less structured curriculum that is reliant on stimulus material that resembles real life (Kang, 1997).

In other words, PBL is not a simple educational strategy but is reliant on a wide range of learning and teaching methods that include problem-solving, inquiry, project-oriented teaching, and case-oriented instruction. It can be defined as a method that provides a problem-solving learning environment through self-directed, team-specific learning activities. PBL is an advantageous method for improving high-level cognitive abilities such as creativity and problem-solving skills, as well as academic achievement. Its effects have been confirmed through studies (Kim \& Kang, 2013).

Unlike traditional teaching methods, the PBL learning method has various effects as learner-centered education that promotes problem-solving under multiple conditions. This has been evidenced in prior research and through learner interactions and various activities.

In conclusion, the higher order thinking skills and attitudes that can result from PBL classes are the core competencies pursued in the new 21 st century educational paradigm. They are very important in university education, as they emphasize professionalism and students' autonomous learning ability. This is also an educational goal (Choi, 2007).

\section{MAKER Education}

As a keyword representative of the Fourth Industrial Revolution, makers create a new "you" out of an existing "nothing" using advanced tools such as 3D printers. This is based on imagination and creativity in the context of a rapidly changing industrial environment and the rise of digital manufacturing technology. "Maker" means a person who creates (Martinez \& Stager, 2013). The maker movement means that anyone can easily invent new ideas and prints using universal 3D printers and practice cultural and social fusion.

Therefore, to solve the fusion and complex themes related to our lives on our own, MAKER education creates results that fit the subject through activities such as making, sharing, and improving using advanced digital tools and materials (Blikstein, 2013). As the MAKER movement has significantly influenced the educational field, and cultural changes with modern society are taking place, it is now called MAKER pedagogy or MAKER education, and various discussions are currently also taking place (Lee, 2017). MAKER educational approaches systematically en- courage the creation or acquisition of knowledge so that students can obtain concrete and creative results using their own learning methods involving repetitive processes (Katterfeldt, 2015).

MAKER education provides a learner-led learning environment that deals with realistic problems in the forms of problem-based learning, inquiry learning, and project-based learning and produces outcomes that can solve problems based on the skills and knowledge acquired (Martinez \& Stager, 2013). In addition, MAKER educational strategies take place step-by-step through tinkering, making, and 'maker-fair' activities, focusing on the creative process. MAKER education can also be interpreted as self-directed and experiential learning. Individuals make choices and decisions according to their own intentions, from thinking of ideas to acquiring the necessary knowledge and making the products themselves (Dougherty, 2013).

In addition, the act of designing and producing original and new prints on one's own is recognized as a different teaching method. It is a value that can be appreciated educationally in the social sense that it emphasizes. Recently, universities are also actively using maker education through the establishment of maker spaces. Starting with Yonsei University's maker space "Y-Valley" and Konkuk University's "Smart Factory," several universities have opened maker spaces to develop creativity and thinking skills. They are actively used with continuous improvement.

\section{The Ulsan University-Type Flipped-based Innovation Teach- ing Method}

The University of Ulsan has introduced and operated Flipped Learning as its representative innovative teaching method since 2016. The number of courses in operation increased rapidly every year, and 200 lectures were conducted over four years. Since the second semester of 2019, the field was called iF-PBL. It is operated in conjunction with Flipped Learning, introducing a specialized PBL teaching method that takes advantage of Ulsan University`s strengths that combine central learning and capstone design. Table 1 shows the introduction and operation of the University of Ulsan's innovative teaching method.

As a result of the researcher analyzing the University of Ulsan's Flipped Learning's operational status over the past four years, many regrets concerning qualitative developnt were evident compared to the quantitative growth in the use of the approach. Therefore, as an alternative, academics aimed to optimize the use of Flipped Learning by developing and applying a teaching method that combines Action Learning, MAKER, PBL, etc. based on elements of Flipped Learning according to student characteristics. This would increase interest in prior learning and combine the advantages of several learning and teaching methods. The design of 
Table 1. Ulsan University Innovation Teaching Method Operation Status

\begin{tabular}{|c|c|c|c|c|c|c|c|}
\hline & & & oed Le & & & iF-PBL & \\
\hline \multirow[t]{2}{*}{2016} & 1st & 8 & 17 & - & & \multirow{2}{*}{$\begin{array}{c}※ 2020-1 \text { Flipped Learning } \\
\text { A type } 9\end{array}$} & \\
\hline & $2 s t$ & 9 & & & & & \\
\hline \multirow[t]{2}{*}{2017} & $1 s t$ & 12 & \multirow[t]{2}{*}{42} & \multirow[t]{2}{*}{+25} & & M type 6 & \\
\hline & $2 s t$ & 30 & & & & $\begin{array}{c}\text { P type } 35 \\
※ 2020-2 \text { Flipped Learning }\end{array}$ & \\
\hline \multirow[t]{2}{*}{2018} & $1 s t$ & 31 & \multirow[t]{2}{*}{64} & \multirow[t]{2}{*}{+22} & & A type 24 & \\
\hline & $2 s t$ & 33 & & & & $\begin{array}{l}\text { M type } 7 \\
\text { P type 29" }\end{array}$ & \\
\hline \multirow[t]{2}{*}{2019} & $1 \mathrm{st}$ & 25 & 67 & \multirow[t]{2}{*}{+3} & & \multirow[t]{2}{*}{13} & \\
\hline & $2 s t$ & 42 & & & 13 & & \\
\hline \multirow[t]{2}{*}{2020} & $1 s t$ & 50 & 110 & \multirow[t]{2}{*}{+42} & 8 & \multirow[t]{2}{*}{19} & +6 \\
\hline & $2 s t$ & 60 & & & 11 & & \\
\hline Total & & & 300 & & & 32 & \\
\hline
\end{tabular}

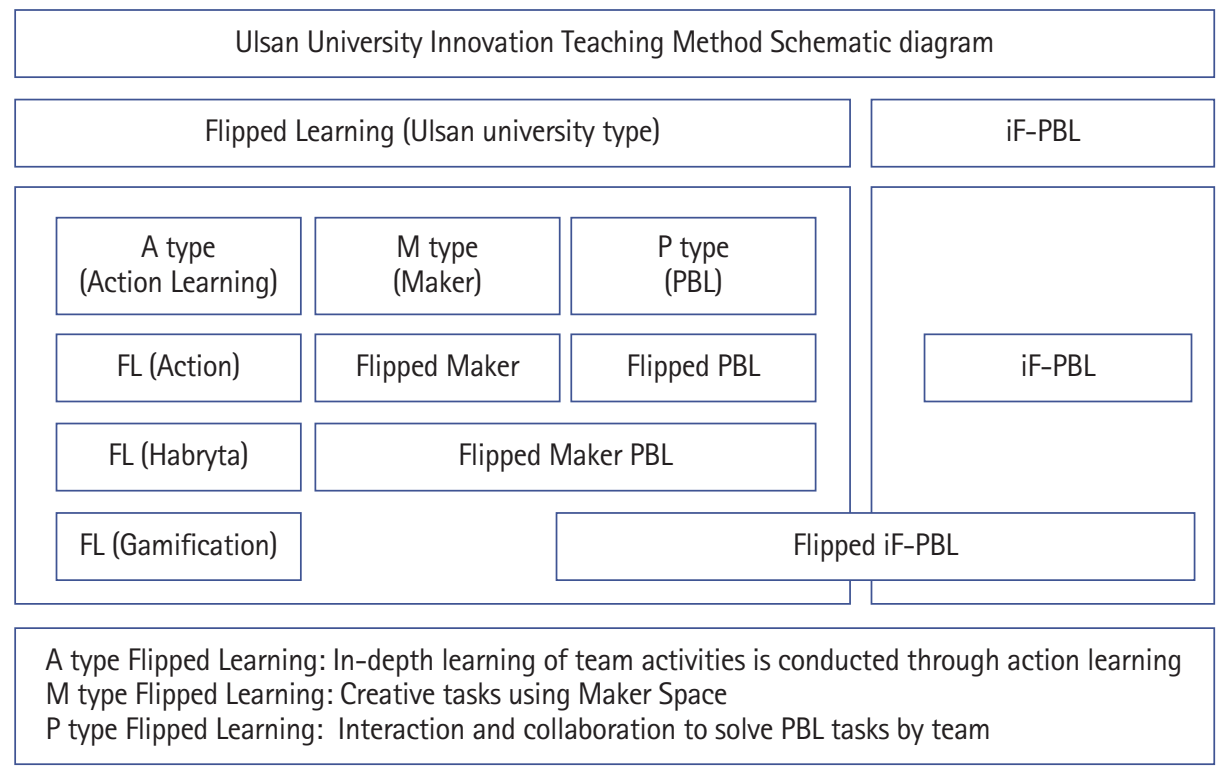

Figure 1. 2020 Ulsan University type flipped learning design (Jeong-phil Hue).

the innovative approach is shown in Figure 1 below. It has been applied and operated since the first semester of 2020 .

The instructional models of Flipped Learning-based PBL and MAKER classes are shown in Figures 2 and 3.

The instructional design was consistent with the basic instructional design of Flipped Learning. Before class, learner-centered activities, interactions, formative evaluation, performance evaluation, etc, were implemented to check learning status and support video learning in advance. After class three stages were designed for the purpose of creating reflection journals and sharing results. Decisions included whether to conduct class as a general learning activity class or to operate it with another innovative teaching method such as PBL or MAKER. The detailed instructional design model is shown in Figure 4 below.
Teachers who applied for Flipped Learning were asked to select the type of activity class according to the research subjects' characteristics and prepare a lesson plan and a study guide suitable for the type of model. In Flipped Learning class design, the learning guidance plan is divided into "Before Class," "In Class," and "After Class." The composition is shown in Table 2 below.

Due to COVID-19, the activity class was operated in a form that allows online interactive activities using Zoom or Webex. In the 110 courses that were operated during the two 2020 semesters, there were three types of online activity classes. First, teambased task activities are a type of group-by-group approach conducted through real-time online video conferences. The second type is a task activity performed by teams through SNS-based interaction. The third and final activity type, combining the two 


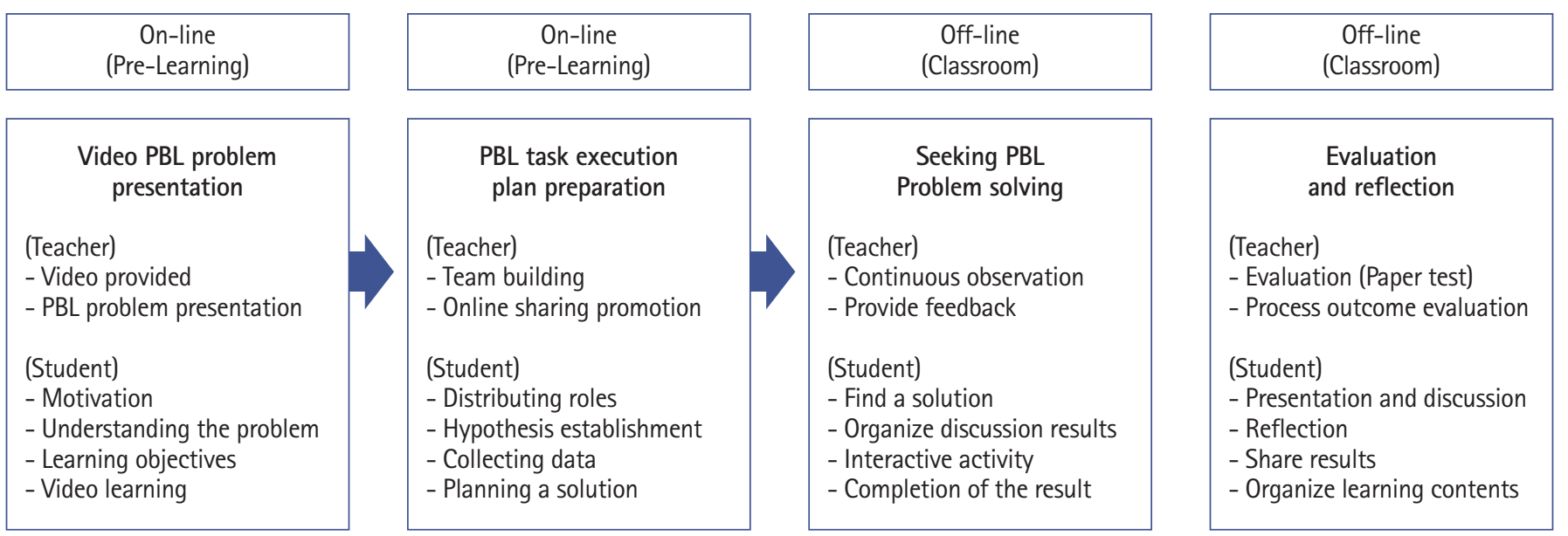

Figure 2. Flipped Learning-based PBL class model (Jeong-Phil Hue, 2017).

\begin{tabular}{|c|c|c|}
\hline $\begin{array}{c}\text { On-line } \\
\text { (Pre-Learning) }\end{array}$ & $\begin{array}{c}\text { On-line } \\
\text { (Pre-Learning) }\end{array}$ & $\begin{array}{l}\text { Off-line } \\
\text { (Classroom) }\end{array}$ \\
\hline $\begin{array}{l}\begin{array}{l}\text { Video Maker problem } \\
\text { presentation }\end{array} \\
\text { (Teacher) } \\
\text { - Video provided } \\
\text { - Maker plan presentation } \\
\text { (Student) } \\
\text { - Motivation } \\
\text { - Understanding Maker plan } \\
\text { - Learning objectives } \\
\text { - Video learning }\end{array}$ & $\begin{array}{l}\quad \begin{array}{l}\text { Maker task execution } \\
\text { plan preparation }\end{array} \\
\text { (Teacher) } \\
\text { - Tinkering } \\
\text { - Online sharing promotion } \\
\text { (Student) } \\
\text { - Establish an action plan } \\
\text { - Theoretical analysis } \\
\text { - Share ideas } \\
\text { - Creative product analysis }\end{array}$ & $\begin{array}{l}\quad \begin{array}{l}\text { Maker activity class } \\
\text { (3D-Printer) }\end{array} \\
\text { (Teacher) } \\
\text { - Continuous observation } \\
\text { - Provide feedback } \\
\text { (Student) } \\
\text { - Creative making activity } \\
\text { - Use of digital tools } \\
\text { - Interactive activity } \\
\text { - Completion of the result }\end{array}$ \\
\hline
\end{tabular}

\begin{tabular}{|l|}
\multicolumn{1}{|c|}{$\begin{array}{c}\text { Off-line } \\
\text { (Classroom) }\end{array}$} \\
\hline \multicolumn{1}{|c|}{$\begin{array}{c}\text { Sharing } \\
\text { and improvement }\end{array}$} \\
(Teacher) \\
- Evaluation (Paper test) \\
- Process outcome evaluation \\
(Student) \\
- Presentation and discussion \\
- Reflection \\
- Share results \\
- Organize learning contents \\
\hline
\end{tabular}

Figure 3. Flipped Learning-based MAKER class model (Jeong-phil Hue, 2019).

\begin{tabular}{|c|c|c|c|}
\hline \multicolumn{4}{|c|}{ Ulsan University Flipped Learning Class Design } \\
\hline Before Class & \multicolumn{2}{|c|}{ In Class } & After Class \\
\hline $\begin{array}{l}\text { Pre-learning materials } \\
\text {-Youtube - Video shooting } \\
\text { - OCW - PDF } \\
\text { - MOOC - Image file } \\
\text { - PPT }\end{array}$ & $\begin{array}{l}\quad \text { Task activity class } \\
\text { - Action learning } \\
\text { - MAKER } \\
\text { - PBL (Problem based Learning) } \\
\text { - PBL (Project based Learning) }\end{array}$ & $\begin{array}{l}\quad \text { Maximize interaction } \\
\text { - Use smart app } \\
\text { - Announcement } \\
\text { - Debate }\end{array}$ & $\begin{array}{l}\quad \text { Reflection journal } \\
\text {-Write a reflection journal } \\
\text { - Team report } \\
\text { - SNS comments }\end{array}$ \\
\hline $\begin{array}{l}\text { Diagnostic evaluation } \\
\text {-Clicker use } \\
\text { - SNS utilization } \\
\text { - LMS utilization } \\
\text { - Quiz questions } \\
\text { - Summary note } \\
\text { - Tree structure }\end{array}$ & $\begin{array}{l}\quad \text { Formative evaluation } \\
\text { - Note test } \\
\text { - Question } \\
\text { - Observe }\end{array}$ & $\begin{array}{l}\text { Performance evaluation } \\
\text { - Report creation } \\
\text { - Portfolio } \\
\text { - Announcement } \\
\text { - Observe } \\
\text { - Essay }\end{array}$ & $\begin{array}{l}\quad \text { Share results } \\
\text { - Use smart app } \\
\text { - SNS utilization } \\
\text { - LMS utilization }\end{array}$ \\
\hline
\end{tabular}

Figure 4. Class design according to flipped learning operation activities 
Table 2. Flipped Learning-based PBL, MAKER class instruction plan

\begin{tabular}{|c|c|c|c|c|}
\hline \multirow{2}{*}{ Class step } & \multirow{2}{*}{ Learning contents } & \multicolumn{2}{|c|}{ Teaching and learning activities } & \multirow{2}{*}{ Place } \\
\hline & & Teacher & Student & \\
\hline Before Class & Video pre-learning & $\begin{array}{l}\text {-Introduction and lecture on theory } \\
\text { through video } \\
\text {-Team Building }\end{array}$ & $\begin{array}{l}\text {-Preparation of lessons through video } \\
\text { pre-learning }\end{array}$ & Home \\
\hline In Class Introduction (15ro & $\begin{array}{l}\text { Learning activity Present- } \\
\text { ing problems }\end{array}$ & $\begin{array}{l}\text {-Presentation of learning goals } \\
\text {-Unit learning activities Introduction to } \\
\text { the problem }\end{array}$ & $\begin{array}{l}\text {-Understand your learning goals } \\
\text {-Identify problems in learning activities } \\
\text {-Activity problem analysis }\end{array}$ & Class \\
\hline In Class deployment (60lo & $\begin{array}{l}\text { Team task Performing ac- } \\
\text { tivities }\end{array}$ & $\begin{array}{l}\text {-Role of facilitator } \\
\text {-Immediate feedback } \\
\text {-Helper role }\end{array}$ & $\begin{array}{l}\text {-Collaboration through interaction } \\
\text {-Active task team activity } \\
\text {-Self-directed learning }\end{array}$ & Class \\
\hline In Class summary $(45 \mathrm{~mm}$ & $\begin{array}{l}\text { Presentation discussion } \\
\text { reflection evaluation }\end{array}$ & $\begin{array}{l}\text {-Direction of presentation and discussion } \\
\text {-Evaluation through comparison of pre- } \\
\text { and post-written tests } \\
\text {-Reflection through the reflection journal }\end{array}$ & $\begin{array}{l}\text {-Participate in presentations and discussions } \\
\text {-Participation in post-writing test } \\
\text {-Evaluation between teams and individual } \\
\text { evaluation } \\
\text {-Reflection through the reflection journal }\end{array}$ & Class \\
\hline After Class & Task execution & $\begin{array}{l}\text {-Preservation of class homeostasis by } \\
\text { presenting assignments }\end{array}$ & -Perform tasks through continuous learning & Home \\
\hline
\end{tabular}

outlined above, is a video conference after team activities. The detailed activity class process is shown in Figure 5 below.

\section{Research method}

The study subjects were students in the 110 Courses and teachers who applied for a course operated by Flipped Learning for the first and second 2020 semesters. The study period comprised two semesters, from March 2020 to December 2020. Consistent with the University protocols for the conduct of research, all participants consented to be involved in the study. The researcher and teachers also provided reflections on the learning processes and outcomes.

To compare the effectiveness of existing Flipped Learning and newly applied Flipped-based PBL and MAKER classes, as a research tool, a pre- and post-interest survey questionnaire was administered to learners. Its purpose was to understand changes in learners' level of interest and their satisfaction with innovative teaching methods. For this purpose, questionnaires surveyed the satisfaction of learners and instructors. The interest rate test paper employed by Jeong-mi Lee (2007) was modified to suit this study's purpose, and its validity was tested after review by five educational engineering experts.

As for the validity test result, the total number of items on the interest scale was composed of 24 items. The scale's overall reliability was very high at 0.996 , indicating that there was an internal agreement of the scale. Sub-factors included emotional motivation, class content, communication, learning activities, expected effects, and satisfaction. Emotional motivation was composed of four questions -reliability 0.980 ; class content - three questions,
Table 3. Question composition for each sub-area of the interest test sheet

\begin{tabular}{llcc}
\hline Sub-factor & \multicolumn{1}{c}{$\begin{array}{c}\text { Question } \\
\text { number }\end{array}$} & Number & $\begin{array}{c}\text { Reliability } \\
\text { (Cronbach's ro) }\end{array}$ \\
\hline Interest & $1-24$ & 24 & 0.996 \\
Emotional motivation & $1,2,8,23$ & 4 & 0.980 \\
Class content & $3,12,14$ & 3 & 0.965 \\
Communication & $5,13,16$ & 3 & 0.967 \\
Learning activity & $4,9,17,21,22$ & 5 & 0.982 \\
Expected effect & $11,15,18,24$ & 4 & 0.971 \\
satisfaction & $6,7,10,19,20$ & 5 & 0.975 \\
\hline
\end{tabular}

reliability 0.965 ; communication three questions - reliability 0.967 ; learning activity - five questions - reliability 0.982 . The expected effect was

4. The reliability was 0.971 , and five questions focused on satisfaction, with reliability of 0.975 . All sub-factor scales had

reliability of 0.900 or higher, which can be said to show internal consistency of the scale. The composition of questions by sub-area of the interest level test sheet is shown in Table 3 below.

In summary, this study selected 110 courses for the classes using Flipped-based PBL and Flipped-based MAKER within Ulsan University in 2020. Through the results of the survey concerning the level of interest and satisfaction with the classes, their effect compared to the existing Flipped Learning was studied. The results focus on their effectiveness and alternatives by analyzing the advantages of grafting together teaching methods with different strengths to bring synergistic effects and identifying what teaching methods fit a subject's characteristics. 


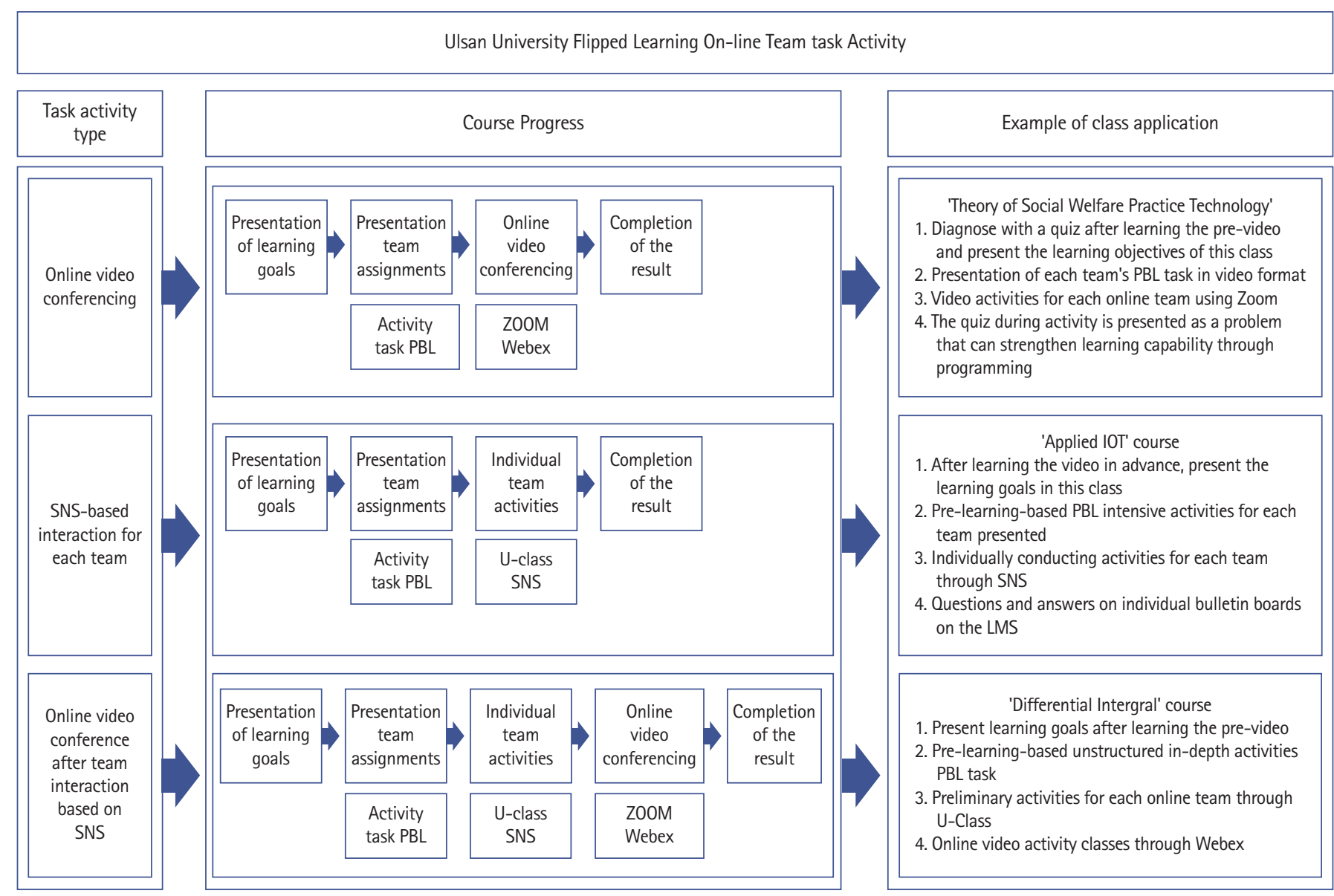

Figure 5. Online team homework activity class.

\section{RESULTS}

\section{Satisfaction with Flipped Learning Class}

In order to find out the effectiveness of the application of the Flipped-based innovative teaching method, which was implemented from 2020, a survey was conducted for the instructor who operated the Flipped Learning class and the learners who participated in the class. These results were compared with the results of the 2019 Flipped Learning class satisfaction survey.

This satisfaction questionnaire used a Likert-style 5-point scale, and the results of the survey were divided into 2019 and 2020 using a t-test. The average analysis results for the satisfaction of Flipped Learning classes in 2019 and 2020 are shown in Table 4.

In the case of instructors, the satisfaction with the class increased by 0.62 points from 4.19 points in 2019 to 4.81 points in 2020 $(p<.001)$, and for learners, the satisfaction with classes increased 0.39 points from 4.23 points in 2019 to 4.62 points in 2020 . The increase $(p<.001)$ was statistically significant. In addition, the overall class satisfaction, including both instructors and learners,
Table 4. Ulsan University Flipped Learning Class Satisfaction Survey Results

\begin{tabular}{lrrrrrrr}
\hline \multirow{2}{*}{ Survey target } & \multicolumn{2}{c}{2019} & \multicolumn{2}{c}{2020} & \multirow{2}{*}{$\mathrm{t}$} & $p$ \\
\cline { 2 - 6 } & $\mathrm{M}$ & $\mathrm{SD}$ & $\mathrm{M}$ & $\mathrm{SD}$ & & \\
\hline Teacher satisfaction & 4.19 & 1.05 & 4.81 & .95 & -24.64 & $0.000^{*}$ \\
Student satisfaction & 4.23 & 1.07 & 4.62 & 1.09 & -19.36 & $0.000^{*}$ \\
Total satisfaction & 4.21 & 1.06 & 4.72 & 1.01 & -20.15 & $0.000^{*}$
\end{tabular}

${ }^{*} p<.001$.

increased 0.51 points from 4.21 points in 2019 to 4.72 points in 2020 ( $p<.001)$, which was statistically significant. In summary, the overall satisfaction of the new flipped-based teaching method class was higher than that of the existing flipped learning class, and in particular, teachers rather than learners showed greater satisfaction with the new flipped-based teaching method class.

\section{Flipped-based PBL and MAKER classes (Pre and post inter- est survey results)}

Pre- and post-interest surveys of 110 lecturers in 2020 focused on whether flipped-based PBL ( $\mathrm{N}=64$ courses $)$ and MAKER 
classes ( $\mathrm{N}=13$ courses) have an effect of improving interest compared to flipped learning classes with action learning alone (N-33 courses) as an educational event. The results of each survey were classified into pre- and post-test using t-test, and the average analysis results are shown in Table 5 .

First, in the case of Flipped Action, which used the existing Action Learning as an activity class, the degree of interest increased by 0.17 points from 3.04 beforehand to 3.21 after. $(p>.05)$, but it was not statistically significant.

Next, in the case of Flipped MAKER, which operated the activity class as a MAKER design based on Flipped, the degree of interest increased by 1.02 points $(p<.001)$ from 2.72 points before to 3.74 points after, showing a significant improvement and being statistically significant.

Finally, in the case of flipped PBL, which operated the flippedbased activity class as PBL, the degree of interest increased by 0.59 points from 2.93 points before to 3.52 points after $(p<.001)$, and it was also statistically significant.

In summary, in all types of flipped learning classes, results suggested interest was improved compared to the pre-investigation results, but the result for the existing action learning approach was not statistically significant.

\section{DISCUSSION}

Many universities have introduced innovative teaching methods according to the changes and demands of the Fourth Industrial Revolution; each has strengths and weaknesses. Educational designs are applied collectively at the school level. However, it is not easy to find one teaching method that fits all the various subjects in many university fields. Therefore, it is necessary to select and apply different teaching methods with proven effectiveness according to the individual characteristics. In this study the survey results showed that flipped learning class activities improved interest in the learning processes.

\section{Flipped-based PBL Class}

The core approach of the PBL class analyzed by this researcher

Table 5. Ulsan University Flipped Learning class pre and post interest survey results

\begin{tabular}{lrrrllll}
\hline \multirow{2}{*}{ Survey target } & \multicolumn{2}{c}{ Pre } & \multicolumn{2}{c}{ Post } & \multirow{2}{*}{$\mathrm{t}$} & $p$ \\
\cline { 2 - 6 } & $\mathrm{M}$ & $\mathrm{SD}$ & $\mathrm{M}$ & \multicolumn{1}{c}{$\mathrm{SD}$} & & \\
\hline Flipped Action & 3.04 & 1.03 & 3.21 & .69 & -7.02 & 0.689 \\
Flipped MAKER & 2.72 & 1.05 & 3.74 & 1.02 & -38.15 & $0.000^{*}$ \\
Flipped PBL & 2.93 & 1.07 & 3.52 & .95 & -28.47 & $0.000^{*}$ \\
\hline
\end{tabular}

${ }^{*} p<.001$. presents the problem first and provides an interactive class for learners to solve problems through teamwork. However, in some actual classes, various problems became apparent due to lack of prior knowledge during classroom activities. As a result, active participation in PBL assignment activities did not occur. There were also problems with students not watching the pre-video well or passively participating in the actual activity of the Flipped Learning class. Therefore, Flipped-based PBL activity classes can increase pre-learning interest by delivering a certain amount of prior knowledge through pre-video learning and adding PBL task introduction to video learning. In addition, even in the actual offline activity class, there is an advantage of increasing the level of interest in the activity class by doing the PBL assignment activity based on an interesting topic in life.

\section{Flipped-based MAKER Class}

Activity classes in Flipped Learning generally have many forms of general action learning. In the process of simply organizing a group and presenting through discussion, many learners did not actively participate, making it challenging to obtain the expected effect. However, if the activity class is conducted by MAKER Education, it is possible to use the latest technological equipment such as 3D printers, and at the same time, there is an effect of maximizing interest in the activity of creating creative creations using various tools.

In the study of the MAKER Education mathematics classes conducted by this researcher, it was seen that many learners were actively participating in activities such as using $3 \mathrm{D}$ printers and laser cutterand it was found that there was a statistically significant effect on improving interest and academic achievement. Therefore, it is believed that the teaching method incorporating MAKER with Flipped Learning can have a positive effect on academic achievement and interest.

\section{CONCLUSION}

It is not easy to find a single teaching method that fits all the various subjects in many university fields. Therefore, it is necessary to select and apply various teaching methods with proven effectiveness according to the subject's characteristics.

The purpose of this study was to discover whether new teaching methods that combine several teaching methods can be applied to suit the characteristics of the subject to show a greater effect. Therefore, through the results of this study, it is expected that the new teaching methods will complement the shortcomings of each teaching method, as well as the possibility of maximizing the strengths of each teaching method, as well as the possibility of se- 
lecting a variety of teaching methods.

This study was conducted on learners of a certain level at a specific university in a particular region. Satisfaction surveys themselves have limitations. Therefore, generalizing the results can be an issue but in future specific guidelines can be applied to the learning processes to make it more likely that goals for optimal student learning are realized.

\section{ACKNOWLEDGEMENTS}

This paper was supported by funding from the Halla Newcastle PBL Education and Research Center. The author acknowledges the editorial support provided by Professor Margaret McMillan.

\section{REFERENCES}

Bergmann, J., \& Sams, A. (2012). Flip your classroom: Reach every student in every class everyday. Oregon. ISTE.

Blikstein, P. (2013). Digital fabrication and ssroom: in education: The democratization of invention. In J. W. Herrmann \& C. Buching (Eds.), FabLabs: Of machines, makers, and inventors (pp. 203-223). Bielefeld, Germany. Transcript.

Choi, Jeong-Im. (2007). A Case Study on Application of Problem-Based Learning in University Classes: Focused on the Effectiveness Analysis through Reflection Diary. Educational Engineering Research, 23(2), 35-65.

Crompton, H., Dunkerly-Bean, J., \& Giannakos, M. (2014). Flipped the classroom in higher education: a design-based research study to develop a flipped classroom framework.

Dougherty, D. (2012). The maker movement. Innovition: Technology, Governance, Globalization, 7(3), 11-14.

Frydenberg, M. (2013). Flipping excel. Information Systems Education Journal, 11(1), 63-73.
Lee, JH., \& Yoon, JY. (2017). A study on the relationship between synesthesia learning development and convergence talent development. Korean Society of Design Culture, 23(1), 491-500.

Johnson, L.., \& Renner, J.. (2012). Effect of the flipped classroom model on a secondary computer application course: student and teacher perceptions, questions and student achievement. unpablished Doctoral dissertation. University of Louisville.

Kang, I. (1997). Why Constructivism?. Seoul. Muneumsa.

Katterfeldt, E. S. (2015). Designing digital fabrication learning environments for Bildung: Implications from ten years of physical computing workshops. International Journal of Child-Computer Interaction, 5, 3-10.

Kim, Hw., \& Kang, I. (2013). A Qualitative Study on the Types and Stages of Learning Outcome of PBL Classes: Focusing on University Research Cases, Education Method Study. Korean Educational Methodology Association, 25(2), 403-427.

Lee, MK. (2015). Upside down classroom, the secret of the class to wake up the sleeping children. Seoul. Salimteo.

Lee, H. (2017). Maker education at the museum in the era of the 4th industrial revolution. Culture and Arts Education Research, 12(2), 83-100.

Martinez, S. L., \& Stager, G. S. (2013). Invent to learn: Making, tinkering, and engineering in the classroom. Torrence, CA, Constructing Modern Knowledge Press.

Tawfik, A. A.., \& Lilly, C.. (2015). Using a flipped classroom approach to support problem-based learning. technology, Knowledge and Learning, 20(3), 299-315.

Toqeer, R. (2013). Flipped classroom concept application to management and leadership course for maximizing the learning opportunities. The Business \& Management Review, 3(4), 137.

Wilson, S. (2013). The flipped class: a method to address the challenges of an undergraduate statistics course. Teaching of Psycholgy, 40, 193-199. 